Most of my cataract cases did not respond to treatment, though some seemed to improve and become stationary. I can mention one cataract case, however, in which resolution seems to have become complete, with restoration of almost full vision.

An eye disease which I have not had the opportunity of treating, but I believe is particularly suitable for diathermy, is trachoma.

In conclusion I would deprecate any extravagant claims for diathermy. Eye diathermy is still in its infancy, but I feel convinced that it has a useful field and will become one of the stock forms of treatment in eye diseases. With time, with more experience and, perhaps with the collective experience of others who have followed me in this line of treatment it may be possible in the future to designate the particular eye diseases which will derive benefit and those in which it is contra-indicated.

Meanwhile, while we are still groping, I continue to say to the ophthalmic surgeons of my hospitals " Send to the Electrical Department any case you find does not respond to any treatment, however hopeless. I can at least promise you that diathermy properly applied to the eye will do no harm."

\title{
TWO CASES OF INTRA-OCULAR SARCOMA
}

\author{
BY \\ HAROLD GRIMSDALE \\ LONDON
}

I THINK short notes of the following two cases of intra-ocular sarcoma are of sufficient interest to justify publication.

Miss J. R., aged 54 years, came to me in January, 1925, with a history that her left eye had recently failed. She had worn glasses for about 5 years for reading; her distant vision had always previously been good in both eyes. She had had her left breast removed for carcinoma 8 years previously; there had been no recurrence. Her right eye was practically emmetropic.

The left pupil reacted to light but vision was reduced to about 1/60. On dilating the pupil, I saw a large detachment of the retina, part of which was clearly filled by a solid mass not much pigmented; the mass was more or less hemispherical in shape and projected forward considerably.

In view of the history, I though it probable that the mass was a recurrence of the original carcinoma: and a similar view was taken by a colleague to whom I showed the patient; but there 
seemed no sign of recurrence elsewhere, so hoping that this might be the sole mass I removed the eye.

On examination the growth proved to be a sarcoma ; presumably it had no relation to the previous disease. When last seen, four years after, the patient remained well.

In this case I was too much obsessed by the history; if I had paid more attention to the character of the shape of the mass, I ought to have recognised it as most probably a sarcoma and not connected with the previous new-growth. Fortunately the mistake in diagnosis made no difference to the patient.

The second case was as follows :-

Mrs. D., aged 0 years, came to me on account of a severely inflamed eye. The right cornea was steamy, allowing only an imperfect view of the parts beneath, but it could be seen that there were posterior synechiae, and vessels in the iris; the lower third of the anterior chamber was occupied by a dark mass; the top of this was blood but the lower part gave me the impression of being not simple clot; there was marked ciliary congestion, and in the lower part were two very large vessels penetrating the sclerotic. I felt a strong suspicion that the iritis was masking a new-growth and as the eye was painful and had very little sight, advised removal: which the patient refused. Under treatment the iritis soon quieted down, the pain ceased and the blood in the anterior chamber absorbed; at the same time the cornea became more transparent.

It was now clear that there was a dark brown mass, apparently pushing through the base of the iris and flattened against the back of the cornea. As I could now speak positively of the presence of a growth the patient agreed to removal. At the first examination. I had attempted to transilluminate the eye but the pupil reflex was so dull that I could not detect any difference, whatever the position of the light; when the iritis had subsided, the lens was found partially opaque, but the slit-lamp seemed to show a considerable mass in the vitreous chamber.

Here the concurrent iritis and hyphaema tended to hide the more serious condition, and caused a slight delay, about 10 days, in the excision. It is to be hoped that the patient has not suffered thereby. 